\title{
WHAT IS THE RESEARCH EVIDENCE FOR USING VISUALIZATION TECHNIQUES IN THE CHEMISTRY CLASSROOM? HOW SHOULD THESE TECHNIQUES BE IMPLEMENTED?
}

\author{
Vickie M. Williamson
}

Texas A \& M University, College Station, Texas, U.S.A.

\begin{abstract}
The goal of chemistry education research is to improve student understanding by investigating the theoretical issues surrounding the teaching and learning of chemistry and by assessing various teaching techniques or strategies in light of these issues. Visualization techniques for the classroom have been proposed in the research literature, but these techniques are often perceived as difficult, confusing, or expensive to implement by instructors. Visualization techniques can involve the use of physical models, role-playing, fixed computer models, student-generated visualizations, animations, and simulations. The use of visualizations in the classroom is believed to promote the formation of mental models of particle behavior, thus increasing students' conceptual understanding. Visualizations can be used individually, sequentially, or simultaneously. When used sequentially, the order of use must be considered, while simultaneous use requires consideration of the design features of the visualizations and where the students focus. Eye-tracking technology can establish the areas of student focus. Another consideration is how the visualizations interact with various student attributes, such as spatial abilities, which can moderate how students comprehend visualizations. The goal of the presentation is to merge research findings and practice considerations in order to promote a smooth implementation of visualizations into the classroom.
\end{abstract}

\section{Theoretical Framework and Background}

When considering the use of visualizations in the classroom, it is important to recognize the theoretical frameworks of our underlying belief in how learning takes place and to have understanding of the difficulty in teaching chemistry. This paper will take a constructivist view of learning. This is the belief that knowledge is construction from interactions with people and materials, not transmitted; that prior knowledge impacts learning; that learning, especially initial understanding, is context specific; and that purposeful learning activities are required to facilitate the construction or modification of knowledge structures (Piaget, 1977; von Glasersfeld, 1995; Osborne, 1983; Bodner, 1986; Johnson-Laird, 1989). Early on the belief was that chemistry should be taught algorithmically or that the focus should be on mathematical problem solving, which would promote both the understanding of problem solving AND understanding of the particulate nature of matter (PNM). However, a number of cross-age studies of students who had training in chemistry showed that misconceptions concerning the PNM existed at all age levels (e.g., Novick \& Nussbaum, 1981; Abraham, Williamson, \& Westbrooke, 1994). Further, researchers found a gap between students ability to respond to algorithmic versus conceptual questions, with a low percentage of students able to answer the conceptual questions, often seen by chemists as easier (e.g., Nurrenbern \& Pickering, 1987; Sawrey, 1990). 
This gap in understanding was especially troublesome as chemists usually explain experimental results using theoretical explanations that usually involve particles and the mathematical description of the phenomena. This difference between chemists and students is found in the expert-novice continuum described by J. Larken (1983). Johnstone (1993) is known for promoting the idea that chemistry is composted of multiple levels, macroscopic, submicroscopic, and symbolic. He further proposed that students have difficulty in understanding the different levels of representation and moving smoothly among them, as experts do seamlessly. The macroscopic level is the representation of the chemical phenomena that students can observe in nature, a demonstration or in the laboratory. The submicroscopic level includes representations of particles and their behavior. The symbolic level can actually be split into the chemical formula or equations and the mathematical representation, giving actually four levels of representation: macroscopic, particulate, symbolic, and mathematical. As instructors, we want to move our students towards a more expert-like capability to move seamlessly among these levels of representation. What can help students understand the particulate level?

What is visualization? The Encarta Dictionary lists these definitions among others: 1) the creation of a clear picture of something in the mind, 2) a clear picture of something created in the mind, 3) a technique whereby somebody creates a vivid positive mental picture of something such as a desired outcome to a problem in order to promote a sense of well-being. For our chemistry students, we want them to understand the PNM by being able to visualize particle behavior or construct mind pictures of particles. If we want students to build mental models of particle behavior, what techniques can we use in the classroom that have research evidence of their worth?

\section{Types of Visualization Techniques}

In their summary article of research studies, Williamson \& Jose (2009) found reported techniques that helped students build mental models at both the macroscopic or particulate levels. The techniques to help build particulate mental models included the use of physical models, role-playing, fixed computer models, dynamic computer models, student-generated depictions, and interactive computer visualizations. Each of these will be discussed.

\section{$2.1 \quad$ Physical Models}

Physical models have been used in chemistry classrooms for some time. This involves the use of concrete, tangible objects that illustrate the chemical structures/processes at the particle level; these have included commercial model kits, food items, balloons, magnets, bungee cords, clay, etc. Gabel and Sherwood (1980) found that students must manipulate the models, not just watch the teacher. While other studies have found that instructors should encourage students to rotate the model to view it from different angles (Gabel and Sherwood, 1980; Friedel, Gable, \& Samuel, 1990). Talley (1973) proposed that models should be used throughout the semester to show structure and interactions. Nicoll (2003) warned that 
students should build the models themselves rather than just be handed one. Researchers also found that instructors should encourage students to make connections between the model and chemistry concepts, asking why is the model build in a certain way and how will the model change in chemical interactions (Ryan \& Herrington, 2014; Talley, 1979). Ryan and Herrington used magnets to represent the particles in dissolving of ionic substances. All studies referenced above found that models aided in understanding of chemistry concepts and performance in solving problems.

\subsection{Role-playing}

Role-playing is a technique in which the students and/or the instructor portray particles in a reaction or a process. This can be accomplished through acting, drama, skits, dance, etc. Space is needed for the role-playing activity, and students must receive positive reinforcement for their participation (Battino, 1979). The literature is divided on how topics should be generated depending on whether this is a project-based activity or is part of the lecture. Battino (1979) proposed that topics to be used for role-playing in lecture must be generated by the instructor and incorporated into lecture at multiple times during the semester. While Lerman (1986) proposed that the students should generate the topics for student projects, but approved by the instructor before students proceed. Both Battino (1979) and Lerman (2003) believe that role-playing may increase student interest and retention in chemistry.

\subsection{Fixed Computer Models}

This technique involves the use of computer images of atoms or molecules whose coordinates are static. These images may be rotated, translated across and toward the screen, or may have different attributes highlighted. These include programs like Jmol, Spartan, etc. Researchers have found that lengthy student sessions with these programs are not required, especially if students work through well-prepared materials (Ealy, 1999; Barnea \& Dori, 1999; Dori \& Barak, 2001). A number of studies report an advantage to having students use a computer program showing fixed models over using physical models (e.g., Barnea \& Dori, 1999; Dori \& Barak, 2001). Dori \& Barak (2001) reported that students who use fixed computer models gave better explanations of structure than those who used physical models. Springer (2014) found significant improvement for students who viewed the manipulation of these fixed computer models during lecture. One study compared the use of three particulate fixed models on students' ability to interpret polarity (Host, Schonborn, \& Palmerius, 2012). These three models were different electrostatic potential representations. While the authors called for more studies, they believe that there may be benefits to reducing visual complexity in the representations used with students.

\subsection{Dynamic Particulate Computer Models}

When using dynamic computer models, the instructor is using a series of images shown in rapid sequence that mimic movement and show a model of the molecular world. This is more 
that just rotating or moving a molecule with fixed coordinates as previously discussed. These include ready-for-viewing movies on computers, DVD, or other media. A large number of particulate animations depicting chemical processes are available from publishers and are on the Internet. Researchers have found that there are benefits for student learning through the use of particulate animations. There seems to be agreement that animations can be short in duration (Williamson \& Abraham, 1995; Burke, Greenbowe, \& Windschitl, 1998) and that animations must be used consistently during the course of instruction (Williamson \& Abraham, 1995). Students can make connections between the particulate and the macroscopic levels when particulate animation and demonstrations/laboratories/video are used conjunctively. By coupling the particulate animations with demonstrations or macroscopic representations, students can begin to move across representations (Russell, et. al., 1997, Burke, Greehbowe, \& Windschitl, 1998). One of the benefits of animations is that students seem to create dynamic mental models that are more representative of nature (Russell, et. al., 1997; Williamson \& Abraham, 1995). All studies cited here reported increase conceptual understanding of chemistry concepts after the use of dynamic particulate computer models.

\subsection{Student-generated}

Visualization techniques include directing students to create their own particulate depictions. A particulate drawing of fixed images can be done with paper and pencil or with a computer program that may optimize angles, but does not use predetermined coordinates (e.g. Marvin Sketch, ChemSketch Freeware, ChemDraw). A dynamic particulate depiction can be created with storyboards/flipbooks or with a computer program like ChemSense or Chemation. Schank and Kozma (2002) proposed that students should be asked to create drawings or animations so that students have to examine their understanding of the chemical phenomena. It may be hard for the instructor to interpret and grade student drawings (Harrison \& Treagust, 1998; Kelly et al., 2010). A detailed scoring rubric may be needed so the instructor can look for key things that show student understanding. Harrison \& Treagust (1998) noted that students should be encouraged to use multiple models or visualization techniques for a concept. All studies cited here used student-generated drawings/animations to evaluate student conceptual understanding.

Milne (1999) reported that assigning students to construct a flipbook of a chemical reaction worked well and engaged students. Milne's work was expanded in one study where second-semester, general chemistry college students were assigned to create storyboards ( $\mathrm{n}=143$ ) or animations ( $\mathrm{n}=157$ ) during a 3-week unit of study on equilibrium (Williamson, Watkins, \& Williamson, 2013). Each student had two assignments, in which they were asked to depict a physical and a chemical equilibrium. These assignments were done such that students in the same laboratory class of 24 had different assignments. The physical equilibrium was done at the end of week one, while the chemical equilibrium was done at the end of week two. The storyboards and animations were submitted and scored using a rubric. 
Scores on a pre-post content and spatial rotation test were also evaluated. Both groups significantly increased in equilibrium conceptual understanding and in spatial rotation ability. However, there were no differences between groups, meaning that with students at this level an instructor can let other factors like computer space or grading help decide which of the two methods to use.

\subsection{Interactive Computer Visualizations}

With interactive computer visualizations, the student sets the variables and directs the actions on the screen. Some experts at a National Science Foundation Workshop suggest that this type of visualization is most beneficial to students as reported in José \& Williamson (2005). Interactive visualizations fit well with the philosophy of constructivism (Abraham, Gelder \& Haines, 2001). Very often these interactive visualizations contain multiple representations, like the macroscopic, the particulate and some form of symbolic or mathematical. Simple laboratory simulations are at the macroscopic level. In order to encourage the construction of particulate mental models of the phenomena being viewed AND apply it to other phenomena, at least one representation needs to be at the particulate level. This is the newest area and has the most need for controlled research studies.

\section{Use of Multiple Visualizations}

Many of the authors cited have called for use of multiple models/visualizations. When using multiple visualizations, there are concerns about the order and level to use. Should the order of use be sequential or simultaneously? Should multiple representation levels be used together?

\subsection{Sequential Visualizations}

Valequez-Marcano et al. (2004) looked at the difference in order between a macroscopic video and a particulate animation of three fluid experiments. The VA group of college general chemistry students $(n=90)$ saw the video followed by the animation, while the AV group $(n=81)$ saw the animation followed by the video. These authors found that there was no preferred order for students to predict the outcomes of the experiments. The macroscopic videos alone (VA) did not evoke maximum performance, probably due to the tenacity of alternate conceptions. Likewise, the particulate animations alone (AV) gave similar results, perhaps because the animation alone was not enough to enable macroscopic mental models. In this study, both types of visualizations are necessary for students to best PREDICT outcomes.

The study was repeated looking for differences in the reason student gave for the phenomena in the three fluid experiments (Williamson et al., 2012). The VA group ( $n=207)$ was compared to the AV group $(n=249)$. Here the findings showed that both videos and animations are needed for maximum percentage of particulate explanations. Further, order does matter. The macroscopic followed by particulate gives the best results. This follows constructivist views of going from the concrete to abstract. 


\subsection{Simultaneous Visualizations}

Williamson et al. (2012) also looked at student success in giving particulate explanations for the phenomena after viewing a video and animation simultaneously. These results seemed to confuse students about the particulate nature of what they are viewing. Leaving the authors to call for more research. When using simultaneous dynamic visualizations, there are at least three potential issues. There may be perception difficulties making it hard to observe relevant processes as reported by Tversky, Morrison, \& Betrancourt (2002). There may be an issue with the increased cognitive load, which may place unnecessary or overwhelming cognitive demands on the student (Ainsworth, 2006; Mayer \& Moreno, 2002). Finally, the ability to deal with simultaneous visualizations may be dependent on cognitive abilities, for example, spatial ability (Cohen \& Hegarty, 2007; Hannus \& Hyona, 1999; Mayer \& Sims, 1994; Harle \& Towns, 2011). In addition, there is the problem of being able to detect what part of the screen a student is observing when simultaneous visualizations are used without using eyetracking technology.

In a study by Hinze et al. (2013), eye tracking was used with the same macroscopic videos and particulate animations used in the previous study by Williamson et al. (2012). Three tests of spatial ability were given to 43 general chemistry students of high and low chemistry knowledge. A mean-split technique was used to group the students into high and low spatial ability. Students were shown the equipment for an experiment and were asked to predict the outcome by selecting what the flasks would look like at the end of the experiment. Next, the video and animation were shown simultaneously, after which students were asked for an explanation of the phenomena. This procedure was repeated for all three fluid experiments. Results showed no difference by chemistry knowledge, but a significant difference by spatial ability. Low spatial ability students preferred to view the particulate animations and more often gave particulate explanations, while high spatial ability students spent more time focusing on the macroscopic video and more often gave physical explanations. The authors proposed that this finding might be due to cueing, that perhaps students understood the task to be macroscopic due to the macroscopic nature of the prediction. In a second study, also reported in Hinze et al. (2013) the experiment was repeated with a group of 41 general chemistry students, who were asked to predict the outcome as before, and a group of 40 general chemistry students who were simply told that they would be asked to explain the scenario after viewing the simultaneous visualizations. Similar results where found. When primed with a macro-level prediction task, higher spatial ability students gave less particulate-level focus and particulate explanation, as found in the first study. When no prediction tasks were given, there was no difference in particulate focus or explanation by spatial ability. A low percentage of students gave particulate explanations thoughout the studies. This led the authors to conclude that overall, students have difficulty reasoning at particulate level when presented with simultaneous dynamic macro/particulate representations. 


\section{Implementation and Summary}

The research literature shows that visualization techniques can be beneficial to students; therefore is worth the instructor's time to implement these into the curriculum. What considerations should an instructor have when trying to implement visualization techniques into the classroom?

- First, plan where visualization fits into your curriculum.

- Decide on whether macroscopic, particulate, or both types of visualizations are needed.

- Choose or find visualizations that suit the classroom facilities, the students, and the learning objectives of the course. Animations and other materials are available from publisher's ancillaries, online, etc. Be sure to observe copyright rules. Use of materials in class is usually allowed if you cite the source and are there is no sale of material to students, but check the rules for your locale.

- Prepare the materials ahead of time. Plan on method of delivery for all activities. Prepare chemicals if you are doing a live demonstration as a macroscopic view.

- Practice the technique before you try to access the website, do a demonstration, etc. in class.

- Recurring usage of visualizations is needed for the maximum student benefit. You can't use just one animation during the entire term of the class and gain much benefit. Visualizations should be used regularly.

- Use more than one visualization technique. Consider using physical models, roleplaying, fixed computer models, student-generated visualizations, animations, and simulations.

- Sequential representations in a lesson seem to be useful with some topics. Consider where these may be needed for students to understand all levels of the concept.

- For sequential visualizations, be aware of order. It seems best to go from macroscopic to particulate to symbolic and mathematical with a topic of study (Williamson, 2011).

- Be aware of the spatial, perceptual, and cognitive load requirements, especially for simultaneous visualizations, as more research is needed with simultaneous visualizations.

Finally, it is important to note that the students will quickly judge whether the visualizations and emphasis on the different representation levels is an assessed part of the course or simply optional enrichment. If instructors want to convey the importance of particulate and macroscopic understanding, then questions on these levels must be included in quizzes and exams. Both mathematical and conceptual questions at the macroscopic and particulate levels should be given.

The quest to improve student understanding of the macroscopic, particulate, symbolic, and mathematical levels is ongoing, adding to our knowledge about techniques that can be used in teaching. The research evidence is clear that we need to engage our chemistry students to develop their understanding of the particulate nature of matter by helping them 
WILLIAMSON

to visualize or develop mental models about chemical phenomena and to help them move towards understanding chemistry on all levels. The use of visualization techniques can promote this understanding. 


\section{References}

Abraham, M.R., Gelder, J. I., \& Haines, K. (2001). Managing information flow for flexible assessment of student learning in large lecture classes. The Chemical Educator. 6(5), 307-308.

Abraham, M. R., Williamson, V.M., \& Westbrook, S.L. (1994). A cross-age study of the understanding of five chemistry concepts. Journal of Research in Science Teaching, 31(2), 147-165.

Ainsworth, S. (2006). DeFT: A conceptual framework for learning with multiple representations. Learning \& Instruction, 16, 183-198.

Barnea, N., \& Dori, Y. J. (1999). High-school chemistry students' performance and gender differences in a computerized molecular modeling learning environment. Journal of Science Education \& Technology, 8 (4), 257-271.

Battino, R. (1979). Participatory lecture demonstrations. Journal of Chemical Education, 56(1), 3941.

Bodner, G.M. (1986). Constructivism: A theory of knowledge. Journal of Chemical Education, 63 , $873-878$.

Burke, K. A., Greenbowe, T. J., \& Windschitl, M. A. (1998). Developing and using conceptual computer animations for chemistry instruction. Journal of Chemical Education, 75(12), 1658-1661.

Cohen, C.A., \& Hegarty, M. (2007). Individual differences in use of an external visualization to perform an internal visualization task. Applied Cognitive Psychology, 711, 701-711.

Dori, Y.J., \& Barak, M. (2001). Virtual and physical molecular modeling: fostering model perception and spatial understanding. Educational Technology \& Society, 4 (1), 61-74.

Encarta World English Dictionary [Computer software] within Microsoft Word 2004, Vers. 11.3.5

Friedel, A. W., Gabel, D. L., \& Samuel, J. (1990). Using analogs for chemistry problem solving: Does it increase understanding? School Science and Mathematics, 9o(8), 674-682.

Gabel, D., \& Sherwood, R. (1980). The effect of student manipulation of molecular models on chemistry achievement according to Piagetian level. Journal of Research in Science Teaching, 17, $75-81$.

Harle, M., \& Towns, M. (2011). A review of spatial ability literature, its connection to chemistry, and implications for instruction. Journal of Chemical Education, 88(3), 351-360.

Hannus, M., \& Hyona, J. (1999). Utilization of illustrations during learning of science textbook passages among low- and high-ability children. Contemporary Educational Psychology, 24, 95123.

Harrison, A.G., \& Treagust, D.F. (1998). Modeling in science lessons: Are there better ways to learn with models? School Science and Mathematics, 98(8), 420-429.

Hinze, S. R., Williamson, V. M., Shultz, M. J., Williamson, K. C., Deslongchamps, G., \& Rapp, D. N. (2013). When do spatial abilities support student comprehension of STEM visualizations? Cognitive Processing - The International Quarterly of Cognitive Science, 14, 129-142.

Host, G. E., Schonborn, K. J., \& Palmerius, K. E. L. (2012). Students' use of three different visual representations to interpret whether molecules are polar or nonpolar. Journal of Chemical Education, 89, 1499-1505.

Johnson-Laird, P.N. (1989). Mental Models. In M. I. Posner (Ed.), Foundations of Cognitive Science (pp. 469-499). Cambridge, MA: MIT Press.

Johnstone, A.H. (1993). The development of chemistry teaching: A changing response to changing demand. Journal of Chemical Education, 70, 701-705

José, T.J., \& Williamson, V. M. (2005). Molecular visualization in science education: An evaluation of the NSF - funded workshop. Journal of Chemical Education, 82 (6), 937-943. 
Kelly, R. M, Barrera, J. H., \& Mohamed, S. C. (2010). An analysis of undergraduate general chemistry students' misconceptions of the submicroscopic level of precipitation reactions. Journal of Chemical Education, 87 (1), 113-118.

Larkin, J. H. (1983). The role of problem representation in physics. In D. Gentner \& A. L. Stevens (Eds.), Mental Models (pp. 75-98). Hillsdale, NJ: Erlbaum.

Lerman, Z. (1986). Energy for art and communication students. Journal of Chemical Education, 63 (2), 142-143.

Lerman, Z. (2003). Using the arts to make chemistry accessible to everyone. Journal of Chemical Education, 8o(11), 1234-1242.

Mayer, R. E., \& Moreno, R. (2002). Animation as an aid to multimedia learning. Educational Psychology Review, 14, 87-99.

Mayer, R.E., \& Sims, V.K. (1994) For whom is a picture worth a thousand words? Extensions of a dual-coding theory of multimedia learning. Journal of Educational Psychology, 86, 389-401.

Milne, R.W. (1999). A low-cost activity for particle conceptualization at the secondary level. Journal of Chemical Education, 76(1), 50-51.

Nicoll, G. (2003). A qualitative investigation of undergraduate chemistry students' macroscopic interpretations of the submicroscopic structure of molecules. Journal of Chemical Education, 80 , 205-213.

Novick, S., \& Nussbaum, J. (1981). Pupils' understanding of the particulate nature of matter: a crossage study. Science Education, 65, 187-196.

Nurrenbern, S.C., \& Pickering, M. (1987). Conceptual learning versus problem solving: Is there a difference? Journal of Chemical Education, 64, 508-510.

Osborne, R. J., \& Wittrock, M. C. (1983). Learning science: A generative process. Science Education, $67,489-508$.

Piaget, J. (1977). The development of thought: Equilibrium of cognitve structures. NY: Viking Press.

Russell, J., Kozma, R., Jones, T., Wykoff, J., Marx, N., \& Davis, J. (1997). Use of simultaneoussynchronized macroscopic, microscopic, and symbolic representations to enhance the teaching and learning of chemical concepts. Journal of Chemical Education, 74(3), 330-334.

Ryan, C., \& Herrington, D. G. (2014). Sticky ions: A student-centered activity using magnetic models to explore the dissolving of ionic compounds. Journal of Chemical Education, 91, 860-863.

Sawrey, B. A. (1990). Concept learning versus problem solving: Revisited. Journal of Chemical Education, 67, 253-254.

Schank, P., \& Kozma, R. (2002). Learning chemistry through the use of a representation-based knowledge building environment. Journal of Computers in Mathematics and Science Teaching, 21(2), 253-279.

Springer, M. (2014). Improving students' understanding of molecular structure through broad-based use of computer models in the undergraduate organic chemistry lecture. . Journal of Chemical Education, 91, 1162-1168.

Talley, L.H. (1973). The use of three-dimensional visualization as a moderator in the higher cognitive learning of concepts in college level chemistry. Journal of Research in Science Teaching, 1O(3), 263-269.

Tversky, B., Morrison, J. B., \& Betrancourt, M. (2002). Animation: Can it facilitate? International Journal of Human-Computer Studies, 57, 247-262.

Velázquez-Marcano, A., Williamson, V. M., Ashkenazi, G., Tasker, R., \& Williamson, K. C. (2004). The use of video demonstrations and particulate animation in general chemistry. Journal of Science Education \& Technology, 13, 315-323.

von Glasersfeld, E. (1995). Radical constructivism: A way of knowing and learning. Wash.,DC.: Falmer.

Williamson, V. (2011). Teaching chemistry with visualizations: What's the research evidence? In D. Bunce, (Ed), Investigating Classroom Myths through Research on Teaching and Learning (pp. 65-81). Washington, DC: American Chemical Society. 
Williamson, V. M., \& Abraham, M. R._(1995). The effects of computer animation on the particulate mental models of college chemistry students. Journal of Research in Science Teaching. 32(5), 521-534.

Williamson, V.M., \& Jose, T.J. (2009). Using visualization techniques in chemistry teaching. In N. J. Pienta, M. M. Cooper \& T. J. Greenbowe (Eds.), The Chemists' Guide to Effective Teaching II (pp.71-88). Upper Saddle River, NJ: Prentice Hall.

Williamson, V. M., Lane, S. M., Gilbreath, T., Tasker, R, Ashkenazi, G., Williamson, K. C., \& Macfarlane, R. D. (2012). The effect of viewing order of macroscopic and particulate visualizations on students' particulate explanations. Journal of Chemical Education, 89, 979-987.

Williamson, V. M., Watkins, J. T., \& Williamson, K. C. (2013). The effect of student-constructed animations versus storyboards on students' mental rotation ability, equilibrium content knowledge, and attitudes. In J. Suits \& M. Sanger, (Eds), Pedagogic Roles of Animations and Simulations in Chemistry Courses (pp. 293-311). Washington, DC: American Chemical Society.

Wu, H., Krajcik, J. S., \& Soloway, E. (2001). Promoting understanding of chemical representations: Students' use of a visualization tool in the classroom. Journal of Research in Science Teaching, 38(7), 821-842.

Yezierski, E. J., \& Birk, J. P. (2006). Misconceptions about the particulate nature of matter: Using animations to close the gender gap. Journal of Chemical Education, 83, 954-960. 